\title{
The Association Between Analgesia Gap and Type of Surgery, Analgesic Drugs, and Timing of Analgesic Administration: What Do We Know?
}

\author{
Susilo Chandra (iD) ${ }^{1,}$, Alfan Mahdi Nugroho ${ }^{1}$, Ikhsan Amran ${ }^{1}$ and Annemarie Chrysantia Melati (iD) ${ }^{1}$ \\ ${ }^{1}$ Department of Anesthesiology and Intensive Therapy, Faculty of Medicine Universitas Indonesia, Cipto Mangunkusumo Hospital, Jakarta, Indonesia \\ "Corresponding author: Department of Anesthesiology and Intensive Therapy, Faculty of Medicine Universitas Indonesia, Cipto Mangunkusumo Hospital, Jakarta, Indonesia. \\ Email: susilochandra@hotmail.com
}

Received 2019 March 20; Revised 2019 April 14; Accepted 2019 April 19.

\begin{abstract}
Background: Inadequate postoperative pain management poses unique challenges for anesthesiologists. The transition from epidural analgesia to other analgesic drugs has its own challenges. Increasing pain during this period is defined as analgesia gap. Objectives: This study aimed at determining the incidence of analgesia gap and its associated factors, such as type of surgery, analgesic drugs, and timing of analgesic administration.

Methods: This was a prospective cohort among acute pain service patients at a tertiary hospital from July to October 2018. There were 220 subjects included in this study. All subjects were scheduled for elective surgery with epidural analgesia. Following last epidural regimen administration, the pain scale was assessed using VAS. If the patient had VAS more than four, then they were classified as having analgesia gap. Type of surgery, type of analgesic drugs, and timing of drugs administration were measured as the associating factors.

Results: The incidence of analgesia gap in this tertiary hospital was $26.6 \%$. Type of surgery was not significantly associated with the incidence of analgesia gap $(\mathrm{P}=0.057)$. However, type of analgesic drugs and timing of analgesic administration were related to incidence of analgesic gap $(\mathrm{P}=0.016$ and $\mathrm{P}<0.001)$.

Conclusions: The incidence of analgesia gap in this study was 26.6\%. Type of analgesic drugs and timing of analgesic administration had a significant association with the incidence of analgesia gap. However, type of surgery did not have a significant association with the incidence of analgesia gap.
\end{abstract}

Keywords: Analgesia Gap, Postoperative Pain, Epidural Analgesia

\section{Background}

Postoperative pain management remains a challenge for anesthesiologist in the past decade (1). The incidence of postoperative pain ranged from $56 \%$ to $80 \%$ (1-3). Postoperative pain is one of the most common problems that causes prolonged hospital stay. If it is not handled properly, postoperative pain will cause more problems for the patient and lead to further medical (wound infections, deep vein thrombosis, and pneumonia) and psychological (depression) complications (2).

At the tertiary hospital, postoperative pain was handled by the acute pain service (APS) team. They consisted of a multi-disciplinary team specifically to manage acute pain, especially postoperative pain. The main goal of this program was to achieve pain-free patients, postoperatively. The APS program is focused on anesthesiologists and nurses, emphasized on modern analgesia therapy, such as the use of patient controlled analgesia (PCA), regional anesthesia, the concept of multimodal analgesia, and latest analgesia therapy (4). Furthermore, the APS team works for 24 hours and ensures that patients feel comfortable postoperatively, considering lower drug's side effects. Tighe mentioned that the APS program can reduce two days of postoperative pain (3). Epidural analgesia remains as the most common choice of postoperative analgesia management since it can be used for both intraoperative and postoperative analgesia.

However, the focus of pain management has shifted due to the APS program. Based on some case reports, it was found that about $12 \%$ of patients complained of pain after 48 hours post-APS. This gap is due to the transition from advance pain management, such as epidural analgesia, to standard analgesia treatment provided in the ward. Increased pain due to gaps in the transition period is called analgesia gap (5). $\mathrm{Ng}$ et al. found that a total of 18 patients (20\%) and nine patients (10\%) experienced an increase in 
pain on the first and second day post-APS (5). Chen et al. found that $33 \%$ requested the use of PCA at 24 hours postAPS, since this method is considered more effective than oral therapy (6). Both studies showed that approximately one-third of patients experienced analgesia gap.

Many factors can influence the occurrence of analgesia gap; pain care management factor is the most influential factor (2). Factors of medical administration are related to analgesia management during APS and post-APS. Giving APS less than 48 hours was associated with an increase of analgesia gap incidence (5). Types of drugs and adherence of drugs administration in the ward influence the risk of pain, 24 hours postoperatively (7).

\section{Objectives}

Currently, there are limited studies analyzing the analgesia gap in clinical practice. This study aimed at determines the incidence of analgesia gap and its associated factors, such as type of surgery, analgesic drugs given, and timing of analgesic administration.

\section{Methods}

This study was a prospective cohort study that identified the incidence of analgesia gap and its associated factors, including type of surgery, analgesic drugs given, and analgesic drug adherence. It was held at a tertiary hospital in Indonesia from July to October, 2018. There were 220 subjects included, following the inclusion and exclusion criteria. The study began after the approval of the research ethics committee.

Inclusion criteria were being an adult patient, fully aware and conscious, having undergone elective surgery with epidural analgesia (thoracic or lumbar epidural), willingness to enter the APS program and still in the care of at least $1 \times 24$ hours post-APS. Exclusion criteria were being unable to assess pain using the visual analogue scale (VAS) and decreased consciousness, postoperatively. All subjects, who agreed to participate, signed the consent form. All subjects underwent anesthesia management in accordance with the preoperative plan. Epidural analgesia was administered for all patients postoperatively in accordance with the anesthesiologist in charge. The dose and duration of epidural analgesia administered was determined by the anesthesiologist.

This study defined analgesia gap as any increased pain scale during the transition period, from the discontinuance of epidural analgesia to oral analgesia. Epidural analgesia was stopped if the patient had VAS less than four. Once the last epidural regimen was administered, pain measurement was conducted using VAS at twelve hours post-APS. If the patient had VAS more than four, then the subject was classified as having analgesia gap. The type of surgery, type of analgesic drugs prescribed, and medication adherence were charted as influencial factors. The type of analgesic drugs prescribed was classified into NSAIDs, acetaminophen, opioids, any combination of two drugs, and patient who received no drug. Meanwhile, timing of analgesic administration was classified as given appropriate timing (after the epidural analgesia has been stopped), not in appropriate timing, and no drug administration.

All data were processed using the program Statistical Package for Social Scientist (SPSS) version 21.0. Bivariate tests were conducted to observe any association between independent and dependent variables.

\section{Results}

There were 220 subjects included in this study with two drop outs; hence, there were 218 subjects analyzed. Demographic characteristics of subjects in the two groups included gender, age, education level, occupation, physical status based on American Society of Anesthesiologists (ASA), and surgical duration (Table 1).

The incidence of analgesia gap was $26.6 \%$ (58 out of 218 subjects). The incidence of analgesia gap that occurred in thoracic surgery was $40 \%$, the upper abdominal operations amounted to $44.8 \%$, in the lower abdominal surgery the incidence was $25.8 \%$ and on the operation of the lower extremities, incidence was $18.3 \%$. Table 2 showed that type of surgery was not significantly associated with analgesia gap.

Table 3 showed an association between type of analgesics administered and analgesia gap. Type of analgesic drugs was significantly associated with analgesia gap. Meanwhile, Table 4 showed the association between medication adherence and analgesia gap.

\section{Discussion}

Appropriate pain management is an essential component in the treatment of postoperative patients. Effective pain management provides comfort to the recovery process and prevents the occurrence of patient morbidity. The occurrence of postoperative analgesia gap will increase morbidity. Analgesia gap is defined as increasing pain during the transition period, especially from the discontinuance of epidural analgesia to oral analgesic drug. This study aimed at determining the incidence of analgesia gap and its associated factors, such as type of surgery, analgesic drugs, and timing of analgesic administration. 


\begin{tabular}{|c|c|}
\hline Characteristics & Values, $N=218^{a}$ \\
\hline \multicolumn{2}{|l|}{ Gender } \\
\hline Man & $90(41.3)$ \\
\hline Woman & $128(58.7)$ \\
\hline Age, $y$ & $46(17-79)$ \\
\hline \multicolumn{2}{|l|}{ Age category, y } \\
\hline $18-29$ & $33(15.1)$ \\
\hline $30-39$ & $28(12.8)$ \\
\hline $40-49$ & $70(32.1)$ \\
\hline $50-59$ & $39(22.5)$ \\
\hline$>60$ & $28(16.2)$ \\
\hline \multicolumn{2}{|l|}{ Level of education } \\
\hline Middle school & $33(15.1)$ \\
\hline High school & $119(54.6)$ \\
\hline University & $65(29.8)$ \\
\hline \multicolumn{2}{|l|}{ Employment } \\
\hline Employee & $61(35.3)$ \\
\hline Workers/farmers & $22(12.7)$ \\
\hline Housewives & $50(28.9)$ \\
\hline Student & $5(2.9)$ \\
\hline Does not work & $17(9.8)$ \\
\hline Entrepreneur & $18(10.4)$ \\
\hline \multicolumn{2}{|l|}{ Physical status } \\
\hline ASA 1 & $19(8.7)$ \\
\hline ASA 2 & $132(60.6)$ \\
\hline ASA 3 & $67(30.5)$ \\
\hline Surgical duration, min & $297(90-890)$ \\
\hline
\end{tabular}

${ }^{\mathrm{a}}$ Values are expressed as No. (\%) or median (min - max).

\begin{tabular}{|c|c|c|c|}
\hline \multirow{2}{*}{ Type of Surgery } & \multicolumn{2}{|c|}{ Analgesia Gap ${ }^{a}$} & \multirow{2}{*}{ PValue $^{\text {b }}$} \\
\hline & Yes & No & \\
\hline Thoracic & $2(40)$ & $3(60)$ & \multirow{5}{*}{0.057} \\
\hline Upper abdomen & $13(44.8)$ & $16(55.2)$ & \\
\hline Lower abdomen & $32(25.8)$ & $91(74.2)$ & \\
\hline Extremity & $11(18.3)$ & $49(81.7)$ & \\
\hline Total & $58(26.6)$ & $160(73.4)$ & \\
\hline
\end{tabular}

${ }^{\mathrm{a}}$ Values are expressed as No. (\%).

${ }^{\mathrm{b}}$ Chi-square, $\mathrm{P}>0.05$.

Baseline characteristics showed that the majority of subjects were in the productive age. In addition, duration

\begin{tabular}{|c|c|c|c|}
\hline \multirow{2}{*}{$\begin{array}{l}\text { Type of Analgesic } \\
\text { Drugs }\end{array}$} & \multicolumn{2}{|c|}{ Analgesia Gap ${ }^{\mathbf{a}}$} & \multirow{2}{*}{ PValue $^{\text {b }}$} \\
\hline & Yes & No & \\
\hline NSAIDs & $11(15)$ & $62(84.9)$ & \multirow{6}{*}{0.016} \\
\hline Acetaminophen & $24(28)$ & $62(72)$ & \\
\hline Opioids & $4(50)$ & $4(50)$ & \\
\hline $\begin{array}{l}\text { Any combination of } \\
\text { two drugs }\end{array}$ & $1(12.5)$ & $7(87.5)$ & \\
\hline $\begin{array}{l}\text { No drug } \\
\text { administered }\end{array}$ & $18(41.9)$ & $25(58.1)$ & \\
\hline Total & $58(26.6)$ & $160(73.4)$ & \\
\hline
\end{tabular}

${ }^{\mathrm{a}}$ Values are expressed as No. (\%).

${ }^{\mathrm{b}}$ Pearson chi-square, $\mathrm{P}<0.05$.

\begin{tabular}{|c|c|c|c|}
\hline \multirow{2}{*}{ Adherence } & \multicolumn{2}{|c|}{ Analgesia Gap ${ }^{\mathbf{a}}$} & \multirow{2}{*}{ P Value $^{\mathrm{b}}$} \\
\hline & Yes & No & \\
\hline $\begin{array}{l}\text { Given in } \\
\text { appropriate time }\end{array}$ & $23(19.0)$ & $98(81.0)$ & \multirow{4}{*}{$<0.0001$} \\
\hline $\begin{array}{l}\text { Given not in } \\
\text { appropriate time }\end{array}$ & $13(26.5)$ & $36(73.5)$ & \\
\hline $\begin{array}{l}\text { No drug } \\
\text { administered }\end{array}$ & $22(54.2)$ & $26(45.8)$ & \\
\hline Total & $58(26.6)$ & $160(73.4)$ & \\
\hline
\end{tabular}

${ }^{\mathrm{a}}$ Values are expressed as No. (\%).

${ }^{\mathrm{b}}$ Pearson chi-square, $\mathrm{P}>0.05$.

of surgery had an important role with regards to surgery stress level (8). Education and employment levels have been associated with pain perception. In this study, 54.6\% of the sample had high school education and 35.3\% worked as employees. All subjects in this study received education regarding VAS to measure their pain scale before surgery.

This study found that type of surgery had no significant association with the incidence of analgesia gap. However, there were uneven types of surgery distribution in this study. The majority of the research subjects underwent lower abdomen and extremities surgeries. However, the incidence of analgesia gap was found highest in thoracic surgery (40\%) and in upper abdominal surgery (44.8\%). Clinically, thoracic and abdominal surgery had higher postoperative pain scale compared to surgery on the limbs and other organs (9). Thoracic surgery was associated with chronic pain due to extensive nerve damage. Therefore, this might explain why the incidence of analgesia gap was found highest in thoracic and upper abdominal surgeries. This might imply that oral analgesic drugs were inadequate to bridge the gap between epidural analgesia to oral medication.

Based on Table 3, it was shown that there was no signifi- 
cant association between type of analgesic drug prescribed and the incidence of analgesia gap. This finding was also consistent with studies of $\mathrm{Ng}$ et al., which showed that analgesia gap could occur with any type of analgesic prescribed, especially in providing analgesic, as low as NSAIDs, acetaminophen or in a combination of two groups of mild and moderate analgesic. Hence, type of analgesic drug did not guarantee that the patient would be pain free. Hence, additional method of pain management should be considered in order to achieve comprehensive postoperative pain management. In this study, the incidence of analgesia gap was found to be lowest with combination of opioids and NSAIDs or acetaminophen, with only one case of analgesia gap. A similar study mentioned that any drug combinations with moderate strength opioid was highly effective to reduce postoperative pain (10). However, patients with prediction of mild postoperative pain usually received non-opioid analgesics. Based on the recommendations of the World Federation of Societies Anesthesiologists, the requirement for parenteral opioids in postoperative patients would be lowered by addition of NSAIDs or acetaminophen.

Timing of analgesic administration was significantly associated with the incidence of analgesia gap. Based on Table 4, it was shown that the incidence of analgesia gap was most prevalent in subjects with no analgesic administered. Unavailability of drugs, due to many reasons, should be handled as soon as possible as this would increase the incidence of analgesia gap. A similar study by Bergeron et al. mentioned that the risk of analgesia gap was increased by withholding of analgesic medications within the first three hours after discontinuation of IV-PCA (11). This study also found that patients, who received analgesics at the appropriate time, had less incidence of analgesia gap. Therefore, timing of analgesics administration was essential to reduce the incidence of analgesia gap. Based on the Institute for safe medication practices (ISMP), provision of maintenance drugs administered over 30 minutes behind schedule would have negative impact on patients and provide suboptimal results $(12,13)$. This study had several limitations. There were limited variables analyzed in this study. There were other factors, which could influence postoperative pain, such as mobility of the patients, surgical site infection, and others. Additionally, history of past surgery, any psychological conditions, such as opioid addiction, the extent of surgery should be included in a future study.

\subsection{Conclusions}

The incidence of analgesia gap in this study was $26.6 \%$. Type of analgesic drugs and timing of analgesic administration had a significant association with the incidence of analgesia gap. However, type of surgery did not have a significant association with the incidence of analgesia gap.

\section{Acknowledgments}

This study was conducted at Cipto Mangunkusumo Hospital.

\section{Footnotes}

Authors' Contribution: Study concept and design: Susilo Chandra, Alfan Mahdi Nugroho and Ikhsan Amran. Analysis and interpretation of data: Ikhsan Amran and Annemarie Chrysantia Melati. Drafting of the manuscript: Annemarie Chrysantia Melati. Critical revision of the manuscript for important intellectual content: Susilo Chandra and Annemarie Chrysantia Melati. Statistical analysis: Ikhsan Amran.

Conflict of Interests: There was no conflict of interest related to this study.

Ethical Approval: This study has been approved by the Ethics Committee.

Funding/Support: There is no funding related to this study.

\section{References}

1. Kehlet H, Jensen TS, Woolf CJ. Persistent postsurgical pain: Risk factors and prevention. Lancet. 2006;367(9522):1618-25. doi 10.1016/S0140-6736(06)68700-X. [PubMed:16698416].

2. Sinatra RS, Jahr JS, Watkins-Pitchford JM. Analgesia gap. The essence of analgesia and analgesics. United Kingdom: Cambridge University Press; 2011. p. 51-6.

3. Tighe PJ. The time course of acute pain in hospitalized patients: Exciting progress in data and methods. Pain. 2016;157(12):2623-4. doi: 10.1097/j.pain.0000000000000714. [PubMed: 27682211]. [PubMed Central: PMC5224868].

4. Meissner W, Coluzzi F, Fletcher D, Huygen F, Morlion B, Neugebauer E, et al. Improving the management of post-operative acute pain: Priorities for change. Curr Med Res Opin. 2015;31(11):2131-43. doi: 10.1185/03007995.2015.1092122. [PubMed: 26359332].

5. Ng A, Hall F, Atkinson A, Leong Kong K, Hahn A. Bridging the analgesic gap. Acute Pain. 2000;3(4):194-9. doi:10.1016/s1366-0071(00)80019-4.

6. Chen PP, Ma M, Chan S, Oh TE. Incident reporting in acute pain management. Anaesthesia.1998;53(8):730-5. [PubMed: 9797515].

7. Gerbershagen HJ, Aduckathil S, van Wijck AJ, Peelen LM, Kalkman CJ, Meissner W. Pain intensity on the first day after surgery: A prospective cohort study comparing 179 surgical procedures. Anesthesiology. 2013;118(4):934-44. doi: 10.1097/ALN.0b013e31828866b3. [PubMed: 23392233].

8. Feldman CH, Dong Y, Katz JN, Donnell-Fink LA, Losina E. Association between socioeconomic status and pain, function and pain catastrophizing at presentation for total knee arthroplasty. BMCMusculoskelet Disord. 2015;16:18. doi: 10.1186/s12891-015-0475-8. [PubMed: 25768862] [PubMed Central: PMC4329215]. 
9. Marsaban A, Bagianto $\mathrm{H}$, Tantri A. Pantuan tatalaksana nyeri periop eratif.In: Chandra S, editor. Perhimpunan dokter spesialis anestesiologi dan reanimasi indonesia. Jakarta. 2009.

10. Ip HY, Abrishami A, Peng PW, Wong J, Chung F. Predictors of postoperative pain and analgesic consumption: A qualitative systematic review. Anesthesiology. 2009;111(3):657-77. doi: 10.1097/ALN.0b013e3181aae87a. [PubMed: 19672167].

11. Bergeron D, Bourgault P, Marchand S. The transition process from patient-controlled intravenous analgesia to as-needed analgesia in postoperative situations: A preliminary look at the issue. Internet $J$ Pain Symptom Control Palliat Care. 2010;8(1). doi: 10.5580/ccb.
12. Prabandari DA, Indriasari I, Maskoen TT. Efektivitas analgesik 24 jam pascaoperasi elektif di RSUP Dr. Hasan Sadikin Bandung Tahun 2017. Jurnal Anestesi Perioperatif. 2018;6(2):98-104. doi: 10.15851/jap.v6n2.1221.

13. Chou R, Gordon DB, de Leon-Casasola OA, Rosenberg JM, Bickler S, Brennan T, et al. Management of postoperative pain: A clinical practice guideline from the american pain society, the american society of regional anesthesia and pain medicine, and the american society of anesthesiologists' committee on regional anesthesia, executive committee, and administrative council. J Pain. 2016;17(2):131-57. doi: 10.1016/j.jpain.2015.12.008. [PubMed: 26827847]. 